\title{
Ct 5,9-10: MEU AMADO É CLARO E CORADO, MAIS DISTINTO DO QUE DEZ MIL
}

\author{
Ct 5,9-10: My BeLOVED IS CleAR AND RuDDY, MORE \\ DISTINGUISHED THAN TEN THOUSAND
}

Susana Aparecida da Silva*

\section{RESUMO}

Como resposta da locução da amada, as filhas de Jerusalém (v. 8) dirigem uma pergunta à amada acerca das razões pelas quais esta está tão aflita à procura do seu amado. É justamente nesse ponto que se inicia a segunda parte do poema (vv. 9-16), objeto do presente estudo. As amigas iniciam seu inquérito à amada com duas perguntas retóricas dirigidas a quem chamam de "mais bela das mulheres" (v. 9d). A pergunta serve como abertura de uma unidade literária. Essa pergunta introduz a descrição que a amada faz acerca da beleza do amado $(5,10-16)$. No v. 10b, há o relato por parte da amada a respeito da figura do amado que se assemelha ao rei de forma inconfundível no meio de uma multidão e parece unir as qualidades dos reis de Israel.

Palavras-chave: Poética hebraica. Cântico dos Cânticos. Amado. Amada.

\section{ABSTRACT}

The daughters of Jerusalem (v.8) ask a question to the female beloved about the reasons why this is so anxious to find his male beloved. It is precisely at this point that begins the second part of the poem (vv. 9-16) of this study object. Her friends begin their inquiry to the female beloved with two rhetorical questions to whom they call the "most beautiful women" (v. 9d). The question serves as opening a literary unit. This question introduces the description of the beloved is about the beauty of the beloved (5.10 to 16$)$. In v. $10 \mathrm{~b}$, there is the reporting by the female beloved concerning the male beloved figure that resembles the king of unmistakable way in a crowd and seems to unite the qualities of the kings of Israel.

Keywords: Hebrew Poetry. Song of Songs. Beloved. Beloved.

* Mestre em Teologia pela Pontifícia Universidade Católica de São Paulo (PUC-SP).

\begin{tabular}{|l|l|l|l|l|l|}
\hline Teocomunicação & Porto Alegre & v. 46 & n. 1 & p. 123-145 & jan.-jun. 2016 \\
\hline
\end{tabular}


A presente pesquisa tem como finalidade a análise exegética de Ct 5,9-10. Este trecho está inserido na unidade literária de $C t$ 5,9-16, a qual contém uma descrição do amado por parte da amada. À questão das filhas de Jerusalém a respeito da superioridade do amado (v. 9), a amada responde com um cântico, um wasf, ${ }^{1}$ no qual exalta o seu amado acima de todos os homens (v. 10). ${ }^{2}$ Para isto, ela descreve alguns traços corporais (vv. 10-15), partindo da cabeça (v. 11), detendo-se em alguns detalhes da face (vv. 12-13), passa pelas mãos, o tronco e as pernas (vv. 14-15) e conclui com uma exclamação de afeto e admiração (v. 16). Como um livro canônico e considerado inspirado, o trecho escrito em linguagem e estilo poético parece conter não somente uma descrição erótica da figura masculina, mas também contém imagens com um simbolismo teológico referente ao Deus do Antigo Israel. ${ }^{3}$ Portanto, é objetivo específico do presente estudo compreender e interpretar $C t$ 5,9-10, no sentido de entender como o Deus e o rei de Israel são caracterizados através da descrição amorosa da amada, que não somente exalta a figura do corpo humano masculino, mas também remete aos símbolos poéticos dos caracteres divinos e reais.

\section{Tradução portuguesa}

Segundo o aparato crítico da Biblia Hebraica Stuttgartensia (BHS, daqui em diante), no v. 9c, em vez de que nos fizestes jurar, há a variante que nos fazes jurar em um fragmento de um códice hebraico da geniza do Cairo. ${ }^{4}$ Com base no texto da edição crítica da $B H S$, a qual procurou apresentar o texto possivelmente mais original, apresento uma tradução inédita feita diretamente do hebraico para o português.
v. 9a "Que é teu amado mais do que um amado,
v. 9b ó mais bela entre as mulheres?
v. 9c Que é teu amado mais do que um amado,
v. 9d de modo que assim nos fizestes jurar?"
v. 10a "Meu amado é claro e corado;
v. 10b mais distinto do que dez mil.

\footnotetext{
${ }^{1}$ Cf. CARR, Lloyd. The Songs of Salomon. An Introduction \& Commentary. Leicester/ Downers Grove: Inter-varsity Press, 2005. p. 140.

${ }^{2}$ Cf. STAdelmanN, Luis. Cântico dos Cânticos. São Paulo: Loyola, 1993. p. 138.

${ }^{3}$ Cf. KEEL, Othmar. The Song of Songs. A Continental Commentary. Trad. Frederick Gaiser. Minneapolis: Fortress Press, 1994. p. 199.

${ }^{4}$ Cf. FRANCISCO, Edson de Faria. Manual da Bíblia Hebraica. Introdução ao Texto Massorético. Guia Introdutória para a Bíblia Hebraica Stuttgartensia. São Paulo: Vida Nova, 2008.
} 


\section{Análise linguístico-estilística}

A estrutura da formulação da pergunta retórica enunciada pelas filhas de Jerusalém (v. 9) faz a transição entre a primeira (vv. 2-8) e a segunda parte (vv. 9-16) o cântico aqui estudado (5,3-6,3). Apresenta uma reação das amigas ao canto da amada, provocando outra reação dela que desemboca na descrição da beleza do amado. ${ }^{5}$ Segundo Albright ${ }^{6} \mathrm{e}$ Pope, ${ }^{7}$ o texto massorético nos versículo 9a e 9c é de difícil compreensão de modo que sua tradução não faz sentido gramatical sem considerar o trecho em relação com a Septuaginta.

\begin{tabular}{|l|l|}
\hline \multicolumn{1}{|c|}{$\boldsymbol{B H S}$} & \multicolumn{1}{c|}{ Septuaginta } \\
\hline $\begin{array}{l}\text { Que é teu amado mais do que um amado, } \\
\text { ó mais bela entre as mulheres? Que é teu } \\
\text { amado mais do que um amado, de modo } \\
\text { que assim nos fizestes jurar? }\end{array}$ & $\begin{array}{l}\text { Que é teu irmãos (amado) entre os irmãos } \\
\text { (amado entre as mulheres? Que } \\
\text { para que assim nos conjures? }\end{array}$ \\
\hline
\end{tabular}

As frases interrogativas pedem informações sobre a descrição do perfil do amado, ou no quê ele se distingue entre os demais amados. Neste sentido, a frase Que é teu amado além de um amado? é perceptível certo grau de diferenciação ou de superioridade. Outro recurso retórico usado no v. 9 é a estrutura da repetição formada pelas perguntas nos v. $9 \mathrm{a}$ e $9 \mathrm{c}$. Ao se dividir o versículo em quatro segmentos se percebe a estrutura $A B A C$.

\begin{tabular}{|c|c|l|}
\hline A & $9 \mathrm{a}$ & Que é teu amado mais do que um amado \\
\hline B & $9 \mathrm{~b}$ & ó mais bela entre as mulheres \\
\hline A & 9c & Que é teu amado mais do que um amado \\
\hline C & $9 d$ & de modo que assim nos fizestes jurar? \\
\hline
\end{tabular}

Se considerar a análise sintática, verifica-se o paralelismo na relação entre os sujeitos de v. 9 b e v. 9 d. De fato, o sujeito do verbo

5 Cf. CAVALCANTI, Geraldo Holanda. O Cântico dos Cânticos. Um ensaio de Interpretação através de suas traduções. São Paulo: Editora da Universidade de São Paulo, 2005. p. 383.

6 Cf. ALBRIGHT, W. F. Archaical Survivals in the text of Canticles. In: THOMAS, Winton; MCHARDY, W. D. (Org.). Hebrew and Semitic Studies Presented to Godfrey Rolles Driver: 1963. p. 4.

7 POPE, Marvin H. Song of Songs. A new translation with introduction and commentary. Vol. 7c. The Anchor Bible. London/New haven: Yale University Press, 1977. p. 531. 
jurar em v. 9d é a "mais bela entre as mulheres" do v. 9b. Dessa forma, o esquema pode ser descrito como ABAB.

\begin{tabular}{|c|c|l|}
\hline A & $9 \mathrm{a}$ & Que é teu amado mais do que um amado \\
\hline B & $9 \mathrm{~b}$ & ó mais bela entre as mulheres \\
\hline A & $9 \mathrm{c}$ & Que é teu amado mais do que um amado \\
\hline B & $9 \mathrm{~d}$ & de modo que assim nos fizestes jurar? \\
\hline
\end{tabular}

Nota-se que os vv. 9a.c versam sobre o amado e os vv. 9b.d se referem á amada como aquela que é mais bela e pediu juramentos. Trata-se de uma resposta ao "refrão de adjuração" presente quatro vezes no livro do $C t$ (cf. 2,$7 ; 3,5 ; 5,8 ; 8,4$ ), transcrito, porém, com algumas variantes no v. $8 .{ }^{8}$ Esse paralelismo denota uma ligação entre $9 \mathrm{~b}$ e $9 \mathrm{c}$.

A estrutura da formulação com base no dispositivo literário dá mais vida à cena. As filhas de Jerusalém pedem uma explicação solene exigindo anuncio da amada com a forma retórica literária no versículo anterior (v. 9) "Que é teu amado mais do que um amado, ó mais bela entre as mulheres? Que é teu amado mais do que um amado, de modo que assim nos fizestes jurar?". O versículo recria a figura do amado desempenhando o estilo poético árabe clássico que geralmente se debruçava sobre a aparência externa geral do amado. ${ }^{9}$

Cavalcante comenta o estilo literário utilizado a partir do v. 10:

Com este versículo inicia-se o wasf do amado, gênero literário raro, pois, normalmente, o que se canta é o corpo da mulher. Não irá surpreender, assim, a maior dificuldade na elaboração das metáforas. Enquanto ao cantar a amada o amante recorre a imagens da natureza, acessíveis e reconhecíveis diretamente, no wasf do amado a sulamita recorre a símiles inanimados, parecendo que as imagens de que se socorre consistem de representações artísticas, donde o comentário da Bíblia de Jerusalém de que possa ter havido na descrição a influência de modelos baseados em estátuas criselefantinas comuns na antiguidade oriental e clássica. ${ }^{10}$

8 JOHNSTON, Gordon H. The Enigmatic Genre and Structure of the Song of Songs. Bibliotheca Sacra, 166, p. 289-305, 2009.

9 ARCONADA, R.; ARSENIO, F. Arsenio; BARTINA, S. La Sagrada Escritura. Texto y comentario. Antiguo Testamento. IV, Los Salmos y los Libros salomônicos. Juan Leal (Org.). Madrid: BAC, 1969. p. 608.

${ }^{10}$ CAVAlCANTE, p. 383. 
O v. 10a tem a forma de uma frase nominal do hebraico, no qual não se usa um verbo no finito. O sujeito destas cláusulas nominais é um nome ou um pronome. No caso do v. 10, o sujeito é a expressão meu amado. Seu predicado pode ser um nome, um pronome, uma frase preposicional, um advérbio ou um infinitivo construto. ${ }^{11}$ No caso do v. 10a tem-se dois adjetivos atributivos, pois modificam-no, se localizam depois do substantivo e concordam com ele em número gênero e definição. ${ }^{12} \mathrm{Em}$ $10 \mathrm{~b}$, tem-se uma frase verbal, cujo sujeito continua sendo meu amado.

$\mathrm{O}$ comentário da amada, juntamente com o v. 16, contempla aspectos gerais da beleza do amado, ao contrário dos vv. 11-15, que ressaltam aspectos específicos de órgãos particulares. ${ }^{13}$

\section{A superioridade do amado}

O personagem amado se insere no cântico sobre os atributos do rei que é composto de sete estrofes. O primeiro atributo, ou seja, a primeira estrofe (v. 9) formula a pergunta retórica enunciada pelas Filhas de Jerusalém que faz a transição entre um cântico e outro, ainda, serve de introdução à prosopopeia (prosopopeia é uma figura de linguagem usada para tornar mais dramática a comunicação) que consiste na descrição esmiuçado da figura do rei (amado). ${ }^{14}$

$\mathrm{Na}$ introdução (v. 9) formulam duas perguntas pelas Filhas de Jerusalém que faz como artifício literário que dá motivo a inserir-se no Cântico a descrição esmiuçada da figura do amado (rei). Tais frases interrogativas pedem dados específicos sobre a identidade do amado, a fim de sanar a curiosidade e o desconhecimento das Filhas de Jerusalém, "pois elas ignoram as características pessoais do esposo". ${ }^{15}$ Segundo Stadelmann "a forma hebraica de especificação da identidade dele pode ser entendida de diversas maneiras, dependendo da preferência pelo sentido de superioridade, de diferenciação ou de igualdade". ${ }^{16}$

${ }^{11}$ Cf. ARNOLD, Bill T.; CHOI, John H. A guide to the Biblical Hebrew Syntax. New York: Cambridge University Press, 2003. p. 165.

${ }^{12}$ Cf. ROSS, Allen P. Gramática do Hebraico Bíblico. 2. ed. Trad. Gordon Chown. São Paulo: Editora Vida, 2008. p. 85.

${ }^{13}$ CASCIARO, José Maria. Cantar de los Cantares.Introducción y notas. In: Sagrada Biblia. Antiguo Testamento. Libros Poéticos y Sapienciales. Traducción y notas. 2. ed. Pamplona: Ediciones Universidad de Navarra, 2005. p. 794.

${ }^{14}$ Cf. STADELMANN, Luis. Cântico dos Cânticos. São Paulo: Loyola, 1993. p. 137.

${ }^{15}$ Cf. CORDERO, Maximiliano García. Cantar de lós Cantares. Introducción y comentário. In: Biblia comentada. Libros Sapienciales. 2. ed. Madrid: BAC, 1967. p. 957.

${ }^{16}$ Cf. STADELmanN, Luis. Cântico dos Cânticos. São Paulo: Loyola, 1993. p. 138. 
No v. 9ab "Que é teu amado mais do que um amado, ó mais bela entre as mulheres?" temos um "artifício literário para introduzir a descrição detalhada do amado". ${ }^{17}$ Para Asensio, a filhas de Jerusalém "fingem uma espécie de indiferente ignorância e arrancam dos lábios da amada uma magnífica descrição do amado". ${ }^{18} \mathrm{O}$ substantivo amado no singular pode designar nas perícope uma espécie ou categoria "de igual em relação a outros". Segundo Stadelmann "com o mim de comparação se exprime a relação de superioridade ou de diferenciação, cuja aplicação à mesma sentença permite traduzi-la de duas maneiras: o que tem teu amado a mais sobre os outros?, ou o que tem teu amado de diferente dos outros?". 19

Para Stadelmann a seleção por uma dessas três traduções depende da interpretação dada ao grupo de pessoas com as quais o amado está relacionado. Afim a identificação do amado em termos descendentes davídico, instituído no cargo de governador, os outros comitês os governantes das províncias de Judá. Sendo que nenhum desses é descendente de uma casa real como o amado se distingue dos demais. Tal diferença essencial é indicada no v. 9ac a distinção do amado, ou seja, a repetição da mesma sentença visa ressaltar a pessoa do rei $($ amado $) .{ }^{20}$

\section{O meu amado é claro}

Como já tratamos do termo meu amado no capitulo anterior, dedicaremos atenção ao primeiro dos atributos do amado: o adjetivo claro ou branco na forma do masculino singular absoluto aparece uma única vez em $C t(5,10)$. Na versão da Septuaginta, o adjetivo $\lambda \in$ $\epsilon$ ó $\varsigma$ está declinado como normal nominativo masculino singular.

\begin{tabular}{|l|l|l|}
\hline \multirow{2}{*}{ v. $\mathbf{1 0}^{\mathbf{a}}$} & $\boldsymbol{B H S}$ & \multicolumn{1}{c|}{ Septuaginta } \\
\cline { 2 - 3 } & Meu amado é branco & Meu irmão é branco \\
\hline
\end{tabular}

${ }^{17}$ Cf. CORDERO, Maximiliano García. Cantar de lós Cantares. Introducción y comentário. In: Biblia comentada. Libros Sapienciales. 2. ed. Madrid: BAC, 1967. p. 957.

${ }_{18}$ ASENSIO, Félix. Cantar de los cantares. Traducción y comentário. In: La sagrada Escritura. Antiguo Testamento. IV. Los Salmos y los Libros salomônicos. Juan Leal (Org.)..Madrid: BAC, 1969. p. 908-909.

19 STADELmanN, Luis. Cântico dos Cânticos. São Paulo: Loyola, 1993. p. 138.

${ }^{20}$ Cf. STADELMANN, Luis. Cântico dos Cânticos. São Paulo: Loyola, 1993. p. 138. 
Há ainda três paralelos na literatura bíblica hebraica: duas vezes em $I s$ 32,4; 18,4 e uma vez em $J r 4,11$. Em Is 18,4, o adjetivo claro é usado no sentido de claridade da luz. Especifica o brilho dos raios de sol: "Porque assim me disse o SENHOR: Estarei quieto, olhando desde a minha morada, como a claridade da luz resplandecente depois da chuva" $(18,2)$. Em Isaías 32,4, o adjetivo claro é usado no contexto da voz clara, ou seja, na clareza do discurso: "E o coração dos imprudentes entenderá o conhecimento; e a língua dos gagos estará pronta para falar com clareza" (Is 32,4). O uso do adjetivo claro em Jeremias revela um sentido diverso das suas ocorrências em Isaías. O adjetivo tem o significado de vibrante ou ardente e está associado ao substantivo vento ou moção: "Naquele tempo se dirá a este povo e a Jerusalém: um vento vibrante das alturas do deserto veio ao caminho da filha do meu povo; não para padejar, nem para limpar" $(4,11)$. A Septuaginta preferiu a esta palavra para traduzir por $\lambda \in \cup \kappa o ́ \varsigma$, que tem dois sentidos: primeiro, claro ou brilhante; segundo, branco. Ambos parecem referir-se diretamente à cor da pele do amado. Diante dessas ocorrências, a amada estava se referindo à cor da pela branca ou clara do amado? $\mathrm{Ou}$ ao seu brilho natural, no sentido de uma pessoa bela, que se distingue entre os demais? Ou ainda, à claridade do discurso do amado? Parece que essa ambiguidade é intencional uma vez que a referência à cor clara da pele do amado pode denotar o gosto pessoal da amada pela cor branca da cútis. A referência à claridade do amado, no sentido de brilho pessoal, devido sua beleza distinta se fundamenta no v. $10 \mathrm{~b}$ que afirma o amado como "mais atraente do que dez mil" ou "distinto entre dez mil", ou ainda "distinto entre uma multidão". Isto faz com que se note um paralelismo entre o adjetivo brilhante ocorrente no v. 10a e o verbo distinguido que ocorre no v. 10b. A tradução como brilhante pode se basear no paralelo externo ao $C t$ que utilizada a palavra (brilhante ou resplandecente) ao se referir aos raios do sol $\left(I_{S} 18,4\right)$. Ademais, Cavalcante apresenta que a tradução de como branco parece ser uma tentativa equivocada de arianização do amado que deveria ser moreno por ser um personagem rural e bronzeado:

É pouco provável que no elogio do pastor a Sulamita o descrevesse como tendo uma tez branca. É verdade que a compleição alvo era atributo da amada ou do amado nos poemas de amor e epitalâmios. Mas isso ocorria, sobretudo, no caso de personagens urbanos. Ora, a Sulamita estaria descrevendo um pastor, homem do campo, 
habitualmente exposto ao sol. Nesse sentido, a tradução da NVI, "O meu amado tem a pele bronzeada", se inexpressiva como imagem poética, tem pelo menos a desculpa da verossimilhança. "Trigueiro" é o termo encontrado na retradução portuguesa de Lucia Mathilde Endlich Orth para a tradução espanhola de Pablo Andiñach. Como a da NVI, faz mais sentido do que as diversas tentativas de arianização do pastor. Mas, em ambos os casos, os tradutores se afastam do texto hebraico que não permite atribuir-se ao amado uma tez morena. ${ }^{21}$

A hipótese de que a clareza se refere ao discurso do amado se fundamenta em Is 32,4 que utiliza este adjetivo para o discurso das pessoas movidas pelo espírito divino. Essa informação a respeito do brilho ou da clareza do discurso do amado será repetida em $C t$ 5,16: "sua boca é muitíssimo suave". Nota-se, assim, a polissemia no uso do adjetivo claro, brilhante, alvo ou branco em Ct 5,10a.

\section{O amado é rosado}

A raiz אָדם aparece oito vezes na BHS (cf. Gn 25,30; Nm 19,2; $2 R s$ 3,22; Is 63,2; Zc 1,82x; 6,2; Ct 5,10). O termo é adjetivo masculino

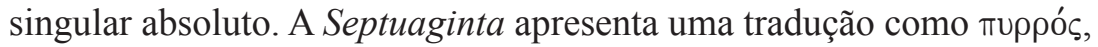
que significa vermelho, à semelhança do fogo, e que pode sugerir a tradução de fogoso. Está declinado como normal nominativo masculino singular.

\begin{tabular}{|l|l|l|}
\hline \multirow{2}{*}{ v. 10a } & \multicolumn{1}{|c|}{ BHS } & \multicolumn{1}{c|}{ Septuaginta } \\
\cline { 2 - 3 } & e rosado & e rosado \\
\hline
\end{tabular}

O uso do vocábulo rosado denota uma aporia no que diz respeito à forma de traduzi-lo no caso v. 10 . Em $G n$ 25,30, o adjetivo é utilizado para caracterizar a coloração do guisado: "E disse Esaú a Jacó: Deixa-me, peço-te, comer desse guisado vermelho, porque estou cansado. Por isso se chamou Edom". A Septuaginta traduziu do mesmo modo. Em Nm 19,2, o adjetivo é atribuído à novilha: "Este é o estatuto

${ }^{21}$ CAVALCANTI, Geraldo Holanda. O Cântico dos Cânticos. Um ensaio de Interpretação através de suas traduções. São Paulo: Editora da Universidade de São Paulo, 2005. p. 384. 
da lei, que o SENHOR ordenou, dizendo: Dize aos filhos de Israel que te tragam uma novilha ruiva, que não tenha defeito, e sobre a qual não tenha sido posto jugo". Já o paralelo presente no $2 R s$ 3,22 estipula um padrão de comparação ao adjetivo vermelho referindo-se ao sangue: "E, levantando-se de madrugada, e saindo o sol sobre as águas, viram os moabitas, defronte deles, as águas vermelhas como sangue". O mesmo fenômeno ocorre no trecho de $I s$ 63,2 o qual compara a cor vermelho com o pigmento liberado pela uva ao ser esmagada no lagar: "Por que está vermelha a tua vestidura, e as tuas roupas como as daquele que pisa no lagar?" Contudo, é o livro de Zacarias que parece conter um paralelo de maior significância para comparação com $C t$ 5,10 ao referir-se duas vezes a cor ruiva ou vermelha dos pelos dos cavalos: "Olhei de noite, e vi um homem montado num cavalo vermelho; e ele estava parado entre as murtas que estavam na baixada; e atrás dele estavam cavalos vermelhos, malhados e brancos" $\left(Z c 1,8^{2 x}\right)$. O mesmo ocorre em $Z c$ 6,2. O estudo desses paralelos não permite resolver a ambiguidade: se a amada se refere à cor אָדם (vermelha) das faces do amado que poderia ser traduzida como rosado; ou se o amado é, de fato, ruivo, com os pelos vermelhos como o pelo dos cavalos do livro de Zacarias ou como a cor dos pelos da novilha do livro dos Números.

A raiz אָרם aparece oito vezes na BHS (cf. Gn 25,30; Nm 19,2; $2 R s$ 3,22; Is 63,$\left.2 ; Z c 1,8^{2 x} ; 6,2 ; C t 5,10\right)$. O uso do vocábulo denota uma aporia no tocante à forma de traduzi-lo no caso v. 10 tanto no sentido da tonalidade do vermelho quanto à exata parte do corpo do amado a que a amada se refere. Vimos que em Gn 25,30, o adjetivo אָרם é utilizado para caracterizar a coloração do guisado e em $I_{s}$ 63,2 refere-se à cor dos pigmentos da uva. Tanto o guisado quanto o vinho são alimentos de degustação prazerosa e saudável, o que pode compor o significado de no cato do vv. 10b como um homem saudável tal como sugere expressões paralelas utilizadas em árabe e notadas por Pope. ${ }^{22}$ Cordero comenta que a cor das faces, geralmente, reflete essa característica, sobretudo, nos jovens, como parecem ser o amado e a amada de $C t .^{23}$

Por outro lado, vimos que o adjetivo אָד é atribuído à novilha de $N m$ 19,2 que parece ter os pelos na cor vermelha ou ruiva. O livro

${ }^{22}$ Cf. POPE, Marvin H. Song of Songs. A new translation with introduction and commentary. Vol. 7c. The Anchor Bible. London/New Haven: Yale University Press, 1977. p. 531.

${ }^{23}$ Cf. CORDERO, Maximiliano García. Cantar de los Cantares. Introducción y comentário. In: Biblia comentada, IV. libros Sapienciales. 2. ed. Madrid: BAC. 1967. p. 957. 
de Zacarias contém duas vezes à cor ruiva ou vermelha dos pelos dos cavalos: "Olhei de noite, e vi um homem montado num cavalo vermelho; e ele estava parado entre as murtas que estavam na baixada; e atrás dele estavam cavalos vermelhos, malhados e brancos" $\left(Z c 1,8^{2 x}\right)$. Com base nesses paralelos, a amada parece se referir à cor אָרם (vermelha) dos cabelos ruivos do amado. Mas o vv. 11 pode desmentir esta hipótese ao falar dos cabelos do amado "negros como o corvo" (Ct 5,11). Assim, o adjetivo vermelho, que traduzimos como corado ou rosado, parece referir-se realmente à cor da pele tal como afirma Stadelmann:

Este verso afirma a nobre linhagem do amado, recorrendo a termos descritivos da cor da pele. A tez "branca" (sah) e "corada" ('adom) caracteriza a aparência dos príncipes, a julgar pelo texto que descreve o aspecto dos jovens da nobreza de Judá, comparando a tez branca com a brancura do leite e a alvura da neve e a tonalidade rubicunda da pele, com o coral ( $\operatorname{Lm} 4,7)$. Uma possível ilustração desse verso pode ser aduzida à base da frase de um canto popular etiópico que menciona a tez branca e corada como indício de nobre linhagem (Lee, VT 21, 609). Tal aparência externa é a característica que torna a figura do rei inconfundível no meio de uma "multidão" (rebaba), lit. "dez mil”, de cidadão comuns. ${ }^{24}$

Desse modo, o adjetivo אָד (vermelho) parece se referir às faces rosadas ou coradas do amado.

\section{Distinto entre dez mil}

O verbo ser distinguido ou distinto ocorre no v. 10b no qal passivo particípio masculino singular absoluto homônimo. Este verbo ocorre somente quatro vezes na $B H S$ (cf. Sl 20,6; Ct 5,10; 6,4.10). Sobre o significa do qal imperfeito, explica Kelley:

No hebraico, o particípio pode estar na voz ativa ou na voz passiva, dependendo do tronco no qual está sendo conjugado. Somente no tronco do qual é que tem tem ambas as formas, o particípio ativo e outro passivo. O passivo talvez seja um resquício de uma voz passiva do qal que, de resto se perdeu. ${ }^{25}$

${ }^{24}$ STADELMANN, Luis. Cântico dos Cânticos. São Paulo: Loyola, 1993. p. 138.

${ }^{25}$ KELLEY, Page H. Hebraico Bíblico. Trad. Marie Ann Wanger Krahn. 4. ed. São Leopoldo: Sinodal, 2003. p. 228. 
No $S l$ 20,6, o verbo está conjugado em qal imperfeito na primeira pessoa comum plural coortativo no sentido: "Nós nos alegraremos pela tua salvação, e em nome do nosso Deus defraudaremos pendões". Foi traduzido na Septuaginta por $\mu \in \gamma \alpha \lambda \nu \nu \theta \eta \sigma o ́ \mu \epsilon \theta \alpha$, (engradeçamos), que é o verbo $\mu \epsilon \gamma \alpha \lambda$ ú $\nu \omega$ no indicativo futuro passivo na primeira pessoa do plural: "Nós nos alegraremos pela sua salvação, e glorificaremos o nome do nosso Deus".

Além de $C t 5,10$, o vocábulo ocorre no refrão repetido em $C t$ 6,4 e $C t$ 6,10: "terrível como um exército embandeirado". Nessa frase,

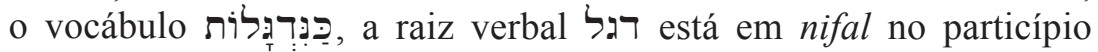
feminino plural absoluto homônimo e está precedida pela partícula prepositiva como e pelo artigo determinativo הָ. Esse refrão foi

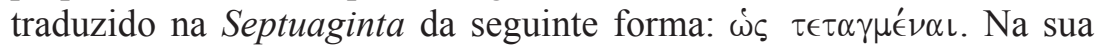
forma grega, o verbo $\tau \dot{\alpha} \sigma \sigma \omega$ está conjugado no particípio perfeito passivo nominativo feminino plural precedido pela conjunção subordinativa $\dot{\omega} s$.

A tradução grega de $C t$ 5,10 também demonstra a aporia na tradução

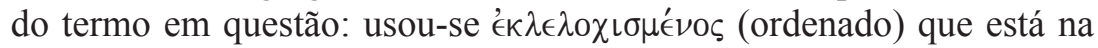
forma do particípio perfeito passivo nominativo masculino singular do verbo $\epsilon \kappa \lambda \circ \chi i \zeta \omega$.

\begin{tabular}{|l|l|l|}
\hline \multirow{2}{*}{ v. 10 } & \multicolumn{1}{|c|}{$\boldsymbol{B H S}$} & \multicolumn{1}{c|}{ Septuaginta } \\
\cline { 2 - 3 } & mais distinto do que dez mil. & eleito entre a multidão. \\
\hline
\end{tabular}

A comparação entre as traduções denota a dificuldade de tradução do termo דá devido ao número limitado de paralelos na BHS e a variedade de traduções realizadas pela Septuaginta.

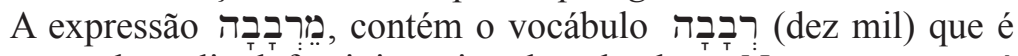
um numeral cardinal feminino singular absoluto. Nota-se que está precedido da preposição (ִ̣tre ou do que) que a Septuaginta optou traduzir por ảmó. A preposição (ִ̣tre ou do que), segundo Walte e O’Connor,

exibe regularmente sua forma canônica 1 antes do artigo e apenas irregularmente de outra maneira; em outras ocorrências, o nun é assimilado pela consoante seguinte e resultam as formas מִ ou

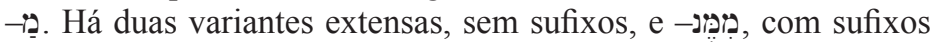


(p. ex., (מִ̣u). As relações que a preposição designa envolvem origens e causas. ${ }^{26}$

Waltke e O'Connor, ao comentar a preposição utilizada em $C t$ 5,10, afirmam a respeito de sua função: “A preposição é um marcador comparativo, prefixado a [...] um grupo para o qual algo é comparado (e assim semelhante a alguns comparativos portugueses)" ${ }^{27}$ Dessa forma, estes autores propõem a seguinte tradução: "mais atrativo do que dez milhares". ${ }^{28}$ De fato, "o comparativo de superioridade ou de inferioridade emprega a preposição $מ$, que é prefixada à palavra que expressa o elemento da comparação". ${ }^{29}$

O numeral cardinal רברבד (dez mil) ocorre dezesseis vezes na $B H S$ (cf. Gn 24,60; Nm 10,36; Dt 32,30; 33,2.17; Jz 20,10; 1 Sm 18,7.8; 21,12; 29,5, Ez 16,7; Mq 6,7; Sl 3,7; 91,7; Ct 5,10; Lv 26,8). Em Ct 5,10, o vocábulo ocorre como um numeral cardinal na forma feminina singular absoluta. Waltke e O'Connor, comentando as passagens de $G n$ 24,60 e $D t 33,7$, que contêm o numeral no plural, comentam: "os numerais maiores são usados no plural como indicadores incertos de grandes magnitudes; neste uso, o numeral usualmente permanece sozinho". ${ }^{30}$ Waltke e O'Connor não são claros ao afirmar que a ocorrência do numeral no singular, como ocorre em $C t 5,10$, possa induzir a uma tradução mais literal fazendo o uso do cardinal "dez mil" ou "dez milhares", mas usaram essa forma no seu livro. Pope é da opinião que a expressão se refere, de fato, a um número grande e indefinido. ${ }^{31}$ Os tradutores da Septuaginta, porém, optaram pela tradução através de um substantivo:

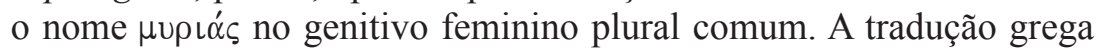
abandonou o uso do numeral traduzível por "dez mil", para o termo grego traduzível por miríade ou multidão.

${ }^{26}$ WALTKE, Bruce K.; O’CONNOR, M. Introdução à Sintaxe do Hebraico Bíblico. Tradução Fabiano Ferreira, Adelemir Garcia Esteves e Roberto Alves. São Paulo: Cultura Cristã, 2006. p. 212.

${ }^{27}$ Ibidem, p. 214.

${ }^{28}$ Ibidem, p. 214.

${ }^{29}$ ROSS, Allen P. Gramática do Hebraico Bíblico. 2. ed. Trad. Gordon Chown. São Paulo: Editora Vida, 2008. p. 87.

${ }^{30}$ WALTKE, Bruce K.; O’CONNOR, M. Introdução à Sintaxe do Hebraico Bíblico. Tradução Fabiano Ferreira, Adelemir Garcia Esteves e Roberto Alves. São Paulo: Cultura Cristã, 2006. p. 281.

${ }^{31}$ Cf. POPE, Marvin H. Song of Songs. A new translation with introduction and commentary. Vol. 7c. The Anchor Bible. London/New Haven: Yale University Press, 1977. p. 531. 


\begin{tabular}{|l|l|l|}
\hline \multirow{2}{*}{ v. 10 } & \multicolumn{1}{|c|}{ BHS } & \multicolumn{1}{c|}{ Septuaginta } \\
\cline { 2 - 3 } & do que dez mil. & entre a multidão. \\
\hline
\end{tabular}

A fim de procurar justificar a tradução pelo numeral em vez do substantivo tal como se realizou na versão grega é necessário considerar

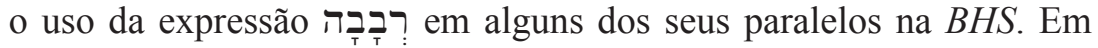
Gn 24,60, o termo רִ רִבְברָ é utilizado na seguinte frase: "E abençoaram a Rebeca, e disseram-lhe: O nossa irmä, sê tu a mãe de milhares de milhares". Nota-se que no grego é precedido por outro numeral $\chi\left\llcorner\lambda\left\llcorner\alpha \dot{\delta} \alpha \varsigma\right.\right.$, mas o vocábulo $\frac{7}{\tau} \frac{7}{\tau}$ ? continuou sendo traduzido por $\mu \nu \rho\llcorner\alpha \dot{\delta} \omega \nu$ (miríades):

\begin{tabular}{|l|l|l|}
\hline \multirow{2}{*}{ Gn 24,60 } & \multicolumn{1}{|c|}{$\boldsymbol{H} \boldsymbol{S}$} & \multicolumn{1}{c|}{ Septuaginta } \\
\cline { 2 - 3 } & milhares de dez mil. & milhares de miríades. \\
\hline
\end{tabular}

No caso de Gn 24,60, embora o numeral esteja no singular, a tradução mais adequada parece ser, de fato, com o uso do substantivo: "milhares de miríades", tal como se fez na Septuaginta.

Em $D t 33,17$ ocorre uma oposição entre o numeral no plural

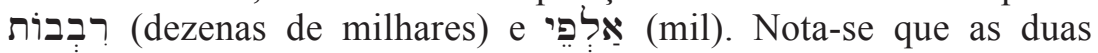
expressões estão no plural e no construto, o que, segundo Waltke e O’Connor, parece ser melhor traduzível com o substantivo multidão ou miríade, em vez do numeral cardinal dez mil.

\begin{tabular}{|l|l|l|}
\hline \multirow{2}{*}{ Dt 33,17 } & \multicolumn{1}{|c|}{ BHS } & \multicolumn{1}{c|}{ Septuaginta } \\
\cline { 2 - 3 } & $\begin{array}{l}\text { A multidão de Efraim e os mil de } \\
\text { Manassés. }\end{array}$ & $\begin{array}{l}\text { A multidão de Efraim e os mil de } \\
\text { Manassés. }\end{array}$ \\
\hline
\end{tabular}

Ez 16,7 traz o caso de que o numeral רברָ רָר com o sentido de advérbio que ressalta a quantidade e não parece ser traduzível pelo numeral "dez mil" embora esteja no singular:

\begin{tabular}{|c|c|c|}
\hline \multirow{3}{*}{ Ez 16,7} & BHS & Septuaginta \\
\hline & 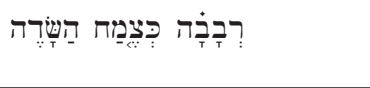 & 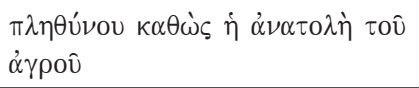 \\
\hline & Aumente a multidão do campo & $\begin{array}{l}\text { Eu te fiz multiplicar como o renovo } \\
\text { do campo }\end{array}$ \\
\hline
\end{tabular}


As demais ocorrências do numeral (cf. $J z 20,10 ; 1 S m$ 18,7.8; 21,12; 29,5, Mq 6,7 e $S l$ 37,91,7) parecem ser traduzível mais precisamente como numeral cardinal dez mil. Diante destas informações, a expressão מֵרברבָה parece exigir uma tradução substantivada como consta na Septuaginta, mas, como analisaremos mais detidamente, os paralelos com o primeiro livro de Samuel e com as ocorrências nos Salmos, baseado na perspectiva histórico-teológica, parecem fundamentar uma tradução mais literal com o uso do numeral cardinal dez mil em vez do nome multidão ou miríade.

A palavra distinto ocorre quatro vezes na $B H S$ (cf. $S l$ 20,6; Ct 5,10; 6,4.10). No Sl 20,6, o verbo está conjugado em qal imperfeito na primeira pessoa comum plural coortativo no sentido: "Nós nos alegraremos pela tua salvação, e em nome do nosso Deus desfraldaremos pendões". Foi traduzido na Septuaginta por $\mu \in \gamma \alpha \lambda \nu \nu \theta \eta \sigma o ́ \mu \in \theta \alpha$, (engradeçamos), que é o verbo $\mu \in \gamma \alpha \lambda \cup$ v́ $\omega$ no indicativo futuro passivo na primeira pessoa do plural: "Nós nos alegraremos pela sua salvação, e glorificaremos o nome do nosso Deus". Em Cânticos, além de 5,10 o vocábulo ocorre no refrão repetido em 6,4 e 6,10: "terrível como um exército embandeirado". Ora, essa informação faz notar o amado como alguém de estatura elevada que se distingue entre a multidão como um pendão acima do exército (cf. Sl 20,6) ou como um soldado mais alto entre os colegas de um mesmo exército em ordem de batalha (cf. Ct 6,4.10). Nota-se a correspondência do elogio feito pela amada ao amado em $\mathrm{Ct}$ 5,10 com o elogio do amado para a amada no duplo refrão de $(C t 6,4.10)$. Ambos se distinguem entre os demais.

Quanto ao numeral cardinal רברבד (dez mil), que ocorre dezesseis vezes na $B H S$ (cf. Gn 24,60; Nm 10,36; Dt 32,30; 33,2.17; $J z$ 20,10; ISm 18,7.8; 21,12; 29,5, Ez 16,7; Mq 6,7; Sl 3,7; 91,7; Ct 5,10; Lv 26,8), deve-se salientar as referências no Primeiro Livro de Samuel: "E as mulheres dançando e cantando se respondiam umas às outras, dizendo: Saul feriu os seus milhares, porém, Davi os seus dez milhares" (1Sm 18,7). Esse trecho do Primeiro Livro de Samuel refere-se à narrativa na qual Davi havia matado o gigante Golias (1Sm 17). A vitória de Davi resultou no triunfo de Israel sobre os filisteus que intentavam escravizar o povo de Deus. Davi obteve a vitória em razão da benção divina e da assistência do Espírito Santo. Essa batalha resultou em uma grande glorificação diante do povo de Israel. As mulheres começaram a cantaras glórias de Davi. A narrativa prossegue com a inveja do rei Saul: "Então Saul se indignou muito, e aquela palavra pareceu mal 
aos seus olhos, e disse: Dez milhares deram a Davi, e a mim somente milhares; na verdade, que lhe falta, senão só o reino?" (1Sm 18,7). Saul não pensava de modo totalmente equivocado. De fato, Davi herdou o reino de Saul foi glorificado nas demais passagens do livro pelo hino cantado pelas mulheres de Israel $(1 S m 21,12 ; 29,5)$. Esse fato marcante da biografia de Davi pode ter sido recebido em dois Salmos nos quais se canta: "Não temerei dez milhares de pessoas que se puseram contra mim e me cercam" $(S l$ 3,7). O mesmo ocorre no Sl 91,7: "Mil cairão ao teu lado, e dez mil à tua direita, mas não chegará a ti". A amada do $C t$ parece também se referir a essa narrativa da história de Davi e atribuir ao amado a glória do antigo monarca (cf. Ct 5,10b). Essa tese reforça a ideia de que a descrição realizada pela amada se refere ao monarca, segundo a teoria literária que interpreta $C t$ como um epitálamo real ou como uma narrativa que contém a presença do monarca de Israel. Por isso, embora Cavalcante afirme "Dez, evidentemente não é uma cifra a reter, mas uma imagem para indicar grande quantidade", ${ }^{32}$ a tradução literal do numeral cardinal רִָרָ (dez mil) somada ao paralelo literal presente na biografia do monarca de Israel Davi, segundo as narrativas do Primeiro Livro de Samuel, parece ser conveniente ressaltar que tanto o amado de $C t$ como o segundo rei de Israel se distinguem "mais do que dez mil", optando-se por uma tradução equivalente à forma do numeral cardinal presente no texto hebraico original.

\section{A beleza da amada}

A amada é qualificada por sua beleza no v. 9b "ó mais bela entre as mulheres" pela forma superlativa, na frase pronunciada pelas Filhas de Jerusalém (cf. Ct 1,8; 5,9; 6,1). O verbo da adjuração é retomado no v. 9d "nos fizestes jurar" a forma verbal do masculino em lugar do feminino é uma construção anômala. ${ }^{33}$

Iniciando a segunda parte do poema, as amigas, impressionadas com os sintomas da doença de amor de sua colega $(C t 5,8)$, perguntaram pelas qualidades especiais do amado: $\mathrm{O}$ que é teu amado mais do que um

\footnotetext{
${ }^{32}$ CAVAlCANTI, Geraldo Holanda. O Cântico dos Cânticos. Um ensaio de Interpretação através de suas traduções. São Paulo: Editora da Universidade de São Paulo, 2005. p. 384.

${ }^{33}$ Cf. STADELmanN, Luis. Cântico dos Cânticos. São Paulo: Loyola, 1993. p. 138.
} 
amado, ó mais bela entre as mulheres? O que é teu amado mais do que um amado, que nos fazes jurar desta maneira? (cf. v. 9). De fato, caso as amigas devam levar uma mensagem a ele, precisam saber reconhecê-lo. ${ }^{34}$ $\mathrm{O}$ tratamento da amada por bela entre as mulheres pode espelhar um sentido irônico. Por outro lado, indica que também ela precisa ter qualidades maiores em termos de beleza, a fim de combinar com ela.

O adjetivo יפה com o sentido de belo, lindo, atraente, elegante ou formoso, ${ }^{35}$ ocorre trinta e oito vezes na $B H S^{36}$ e é atribuído a diversos sujeitos na literatura bíblica. As sete vacas sonhadas por José eram chamadas de belas (cf. Gn 41,2.4.18) e o monte Sião é chamado de uma bela elevação (cf. $S l$ 48,3). Nas tradições jurídicas legisla-se também sobre a mulher bela pela qual o israelita se apaixonar entre os inimigos cativos, a qual deve ser sujeita a específicas determinações legais (cf. Dt 21,11). Na literatura profética, ao criar-se metáforas para explicar a situação do povo, os profetas atribuíram o adjetivo a várias imagens. $\mathrm{O}$ povo recebe na profecia de Jeremias uma comparação com uma bela oliveira cercada de cuidados pelo SENHOR Deus (cf. $J r$ 11,16). Na profecia de Ezequiel, o reino da Assíria é comparado a um cedro do Líbano com belas ramagens (cf. Ez 31,3). As árvores do jardim de Deus também são belas (cf. Ez 31,9). Ezequiel é consolado pelo SENHOR como alguém que entoou uma música agradável com uma bela voz para o povo, mas este não correspondeu (cf. Ez 33,32). Qualificam-se de belas as virgens em Amós (cf. Am 8,13).

Entretanto, são as narrativas bíblicas que podem sugerir maior entendimento da beleza na literatura bíblica devido à caracterização de alguns personagens como adjetivo belo. Sarai, esposa de Abraão, é chamada de bela duas vezes, uma das quais com o advérbio (muito) (cf. Gn 12,11.14). Raquel é chamada de bela assim como sua face (cf. 29,17). Ester (cf. Est 2,7), Abigail (cf. 1 Sm 25,3) e Tamar, irmã de Absalão (cf. 2Sm 13,1;14,27) também são chamadas de bela. Quando o rei Davi ordenou que se procura uma moça bela em toda terra de

\footnotetext{
${ }^{34}$ Cf. POPE, Marvin H. Song of Songs. A new translation with introduction and commentary. Vol. 7c. The Anchor Bible. London/New Haven: Yale University Press, 1977. p. 531.

35 ALONSO SCHÖKEL, Luis. Dicionário Bíblico Hebraico-Português. 3. ed. São Paulo: Paulus, 2004. Voz פפי". p. 285.

${ }^{36}$ Cf. Gn 12,11.14;29,17; 39,6; 41,2.4.18; Dt 21,11; 1 Sm 16,12;17,42; 25,3; 2 Sm 13,1; 14,25.27; IRs 1,3.4; Jr 11,16; Ez 31,3.9; 33,32; Am 8,13; Sl 48,3; Jó 42,15; Pr 11,22; Ct $1,8.15 .16 ; 2,10.13 ; 4,1.7 ; 5,9 ; 6,1.4 .10 ;$ Ecl 3,11; 5,17; Est 2,7.
} 
Israel encontrou Abishag, a Sunamita, que com ele coabitou e cuidou do monarca envelhecido (cf. $l R s$ 1,3.4). Não foi encontrada em toda terra filhas tão belas como as de Jó (cf. Jó 42,15).

Quanto aos homens presentes nas narrativas bíblicas, José também é qualificado como de bela aparência (cf. Gn 39,6). Absalão era estimado em todo Israel justamente em razão da sua beleza (cf. $2 \mathrm{Sm}$ 14,25). Davi é descrito como ruivo, de aparência agradável com belos olhos (cf. 1Sm 16,12). Em outro trecho Davi também é descrito como de bela aparência.

$\mathrm{Na}$ literatura sapiencial, Provérbios apresenta uma sentença sobre a mulher formosa: "Como jóia de ouro no focinho de uma porca, assim é a mulher bela que não tem descrição" (cf. $\operatorname{Pr} 11,22$ ). Em Eclesiastes afirma-se que Deus a tudo fez belo em seu tempo (cf. Ecl 3,11) e qualifica-se de bela coisa "comer e beber, e gozar cada um do bem de todo o seu trabalho, em que trabalhou debaixo do sol, todos os dias de vida que Deus lhe deu" (cf. Ecl 5,17).

Em $C t$, o adjetivo belo treze vezes (cf. $C t$ 1,8.152.16; 2,10.13; $\left.4,1^{2} .7 ; 5,9 ; 6,1.4 .10\right)$. A primeira referência ocorre justamente em um diálogo entre a amada e o amado. Esta pergunta ao seu amigo onde ela descansa e onde apascenta os seus rebanhos (cf. Ct 1,7). Este lhe responde chamando-a justamente de ó mais bela entre as mulheres (cf. Ct 1,8), justamente com a mesma formulação usada pelas filhas de Jerusalém em diálogo com a amada em $C t$ 5,8. O capítulo primeiro de $C t$ se finaliza com uma troca de elogios entre o casal: "Como és bela, minha amada, como és bela!... Teus olhos são pombas. Como és belo, meu amado, e que doçura! Nosso leito é todo relva" (cf. Ct 1,15-16). Nesses dois versículos o adjetivo belo ocorre três vezes.

No segundo poema (cf. Ct 2,8-17) há mais duas ocorrências do adjeto belo. A esposa imagina seu amado invocando-a: "Levanta-te, minha amada, bela minha, vem a mim" $(C t 2,10)$. Essa frase é repetida literalmente mais a frente, no v. 13, com a forma de estrofe em um paralelismo perfeito com o v. 10. Nota-se que não é o amado quem elogia a amada mais é a própria amada que imagina ser elogiada pelo amado numa espécie de sonho que não se sabe se é de olhos abertos.

Logo no primeiro verso do quinto poema (cf. Ct 4,1-5,1), ocorre mais duas vezes o adjetivo belo: "Como és bela minha amada, como és bela!" $(C t 4,1)$. Nota-se um que entre essas ocorrências e a próxima no mesmo poema $(C t 4,7)$ o amado faz uma descrição dos atributos físicos 
de sua amada (cf. Ct 4,2-6). Ele fala dos olhos, cabelo, dentes, lábios, fala, faces, pescoço e seios numa descrição que começa de cima para baixo, da cabeça aos seios. Essa descrição finaliza com o paralelismo em uma a exclamação que sintetiza a beleza da amada: És toda bela, minha amada, e não tens um só defeito!"' (Ct 4,7). Trata-se de uma idealização da amada que é apresentada pelo amado, sem defeito, sem algo que poderia lhe deixar mais bela, ou seja, perfeita.

No capítulo sexto do $C t$ há mais três ocorrências do adjetivo belo. $\mathrm{O}$ coro, que bem pode ser mais uma vez as filhas de Jerusalém, que se dirigiram à amada do mesmo modo em 5,9 , repetem o elogio perguntando à moça onde anda seu companheiro: "Onde anda o teu amado, ó mais bela das mulheres? Aonde foi o teu amado? Iremos buscá-lo contigo!" $(C t 6,1)$. A moça responde que o amado é seu, pois ele já desceu ao seu jardim, o que pode significar o ato sexual; e para não deixar margem à disputas pelo seu amado com as demais filhas de Jerusalém ela afirma a mútua possessão entre o casal: "E sou do meu amado e meu amado é meu" (Ct 6,3).

As demais ocorrências do adjetivo belo, embora no mesmo capítulo, parecem pertencer a outra unidade literária, ao oitavo poema. Esta canção seria mais uma declaração do amado acerca da sedução irresistível da mulher em razão d sua beleza. Nota-se o paralelismo entre o primeiro verso e o último verso no qual se repete o adjetivo bela (cf 6,4.10). A primeira ocorrência seria a exclamação "És bela, meu amor, és como Tirza, aprazível como Jerusalém, terrível como um exército com bandeiras" (Ct 6,4). No versículo final do oitavo poema, em vez de comparar a amada à cidade mais sagrada dos hebreus, compara-se sua beleza com a beleza da lua, que preside os astros celestes durante a madruga: "Quem é esta que aparece como a alva do dia, formosa como a lua, brilhante como o sol, terrível como um exército com bandeiras?" $(C t 6,10)$. Nota-te na estrutura estilística do oitavo poema que além do paralelismo com o elogio da beleza da amada há também o paralelismo da comparação como o exército com bandeiras.

Ao analisar as ocorrências do adjetivo belo ou bela em $C t$, notase que é o elogio supremo à amada. Há a significativa ocorrência de doze vezes do adjetivo que no simbolismo da numerologia bíblica significa plenitude e relembra a beleza divina que é plena ou perfeita (cf. $\operatorname{Pr} 11,22$ ). Dois poemas se iniciam com este elogio, a saber, o quinto poema (cf. $C t$ 4,1-5,1) e oitavo poema (cf. $C t$ 6,4-10). Esse uso estilístico denota que chamar a amada de bela é uma forma de delimitar 
alguns poemas tal como se faz no trecho em estudo que se inicia com o elogio da beleza da amada por parte das filhas de Jerusalém $(C t 5,9)$. Ademais, o adjetivo bela parece ser o elogio que mais compraz a amada uma vez que ela mesma imagina a fala do seu amado iniciandose com esse adjetivo. E, de fato, o elogio do amado fala da beleza perfeita da amada no qual afirma repetidamente que este é linda, sem defeito.

Pode-se dizer, ademais, que ao chamar a amada de bela ou linda recordar-se a beleza de algumas poucas, contudo, as mais belas mulheres da história dos patriarcas. Relembra-se a beleza de Sara, a esposa do primeiro entre os Patriarcas,o pai universal Abraão. Sarai, esposa de Abraão, é chamada de bela duas vezes, uma das quais com o advérbio בְאר (muito) (cf. Gn 12,11.14). Tal era a beleza de Sara que encantou o faraó do Egito e um dos reis cananeus a ponto de que Abraão teve que apresentar-se como parente de Sara e não como esposo a fim de não correr perigo de vida devido a atração que sua esposa poderia provocar e como de fato se deu, entre os monarcas que a conheceram. Raquel é chamada de bela e teve sua elogiada com o mesmo adjetivo (cf. 29,17). Ester (cf. Est 2,7), Abigail (cf. 1Sm 25,3) e Tamar, irmã de Absalão (cf. $2 S m$ 13,1; 14,27) também são chamadas de bela. Quando o rei Davi ordenou que se procurasse uma moça bela em toda terra de Israel encontrou Abishag, a Sunamita, que com ele coabitou e cuidou do monarca envelhecido (cf. $1 R s$ 1,3.4).

Nota-se, por fim, que além do contexto patriarcal, quase todas as mulheres presentes nas narrativas bíblicas que mereceram ser chamadas de belas ou lindas foram princesas da corte dos reis de Judá e Israel, com exceção do caso de Ester, que foi rainha na corte estrangeira e das filhas de Jó.

\section{O juramento no contexto matrimonial}

Em $C t$ 5,9, a raiz verbal de conjurar, de modo completamente diferente das demais ocorrências, nas quais a amada conjura as filhas de Jerusalém, nessa passagem, são as filhas de Jerusalém que conjuram a amada acerca das qualidades do seu amado para que esta o considere acima dos demais homens. Elas exigem uma resposta da amada. Esta se sente obrigada a descrever as qualidades físicas do seu amado.

Em diversas passagens da $B H S$, o verbo conjurar, no Hifal, tem o sentido de juramento (cf. Gn 50,5.6.25; Ex 13,19; Js 2,17; 2,20; 6,26; 
23,7; Nm 5,19.21; 1 Sm 14,27.28.20.17; 1Rs 2,42; 18,10; 22,16; 2Rs 11, $14 ; E d 10,5 ; \mathrm{Ne} 5,12 ; 2 \mathrm{Cr} 18,15 ; 36,13)$. Entretanto, por três vezes na $B H S$, o verbo jurar ocorre em um contexto matrimonial.

Em Nm 5,19.21, o verbo conjurar também é utilizado em contexto matrimonial. Por imprecação do sacerdote, a mulher casa deveria jurar que não tivera relação extraconjugal sob pena de ser amaldiçoada. Em Gn 24,4.37, o verbo conjurar ocorre em um contexto onde se narra o casamento de Isaac com Rebeca, Abraão exige que o seu servo jure que não permitirá que Isaac tome uma mulher cananeia como esposa, exigindo que fosse da sua parentela. A mesma ideia se dá em $\mathrm{Nm}$ 13,25:

$\mathrm{Eu}$ os repreendi e invoquei maldições sobre eles. Bati em alguns deles e arranquei os seus cabelos. Fiz com que jurassem em nome de Deus e lhes disse: Não consintam mais em dar suas filhas em casamento aos filhos deles, nem haja casamento das filhas deles com seus filhos ou com você.

Será que $C t$ 5,8.9 não quer relembrar o uso do mesmo verbo o juramento do servo de Abraão como uma das qualidades exigidas pelas filhas de Jerusalém para que o amado seja realmente superior aos demais?

\section{Conclusão}

A respeito do v. 9: "Que é teu amado mais do que um amado, ó mais bela entre as mulheres? Que é teu amado mais do que um amado, de modo que assim nos fizestes jurar?", deve-se dizer que é artifício literário feito pelas filhas de Jerusalém à amada em forma de duas perguntas retóricas (vv. 9ab e 9cd) iniciadas cada uma por uma anáfora ${ }^{37}$ literalmente idêntica (vv. $9 \mathrm{a}$ e $9 \mathrm{c}$ ). O texto salienta a aparência das duas personagens protagonistas dos cânticos: o amado e a amada. No caso do amado, fala-se apenas da comparação de superioridade (vv. 9a e 9c) que a amada, na sequencia do texto (vv. 9-16), resume em descrições da sua aparência física; mas no caso da amada, usa-se o epíteto $^{38}$ superlativo de bela que era usado para personagens femininas

\footnotetext{
${ }^{37}$ Anáfora é a repetição da mesma palavra ou grupo de palavras no princípio de frases ou versos consecutivos.

${ }^{38}$ Epíteto é um substantivo, adjetivo ou expressão que se associa a um nome para qualificálo e, pode ser aplicado a pessoas, divindades, objetos.
} 
importantes das tradições narrativas bíblicas, tais como, Sara ( $G n$ 12,11.14), Raquel (Gn 29,17), Ester (Est 2,7), Abigail (1Sm 25,3), Tamar $(2 S m 13,1 ; 14,27)$ e Abishag, a Sunamita (1Rs 1,3.4). A locução das filhas de Jerusalém (v.9) é uma ação que prepara a reação da amada que responde com a descrição da aparência física do amado (vv. 10-16), ${ }^{39}$ que apresentará "visos de idealização poética em conformidade com a profundidade do amor". ${ }^{40}$ Os versículos subsequentes formarão uma espécie de "retrato poético do amado". ${ }^{41}$

Do ponto de vista da análise linguístico-estilística, o v. 10 contém duas frases nominais com o mesmo sujeito (meu amado). A primeira frase, "o meu amado é claro e corado" (v. 10a), é nominal e predicativa. É formada por um substantivo com sufixo pronominal meu amado que exerce a função sintática de sujeito e dois adjetivos claro e corado interligados por uma preposição $e$. Esses adjetivos possuem a função sintática de predicativo do sujeito. Essa construção ([é] claro e corado) exerce a função sintática de predicado nominal do sujeito (meu amado). A frase não contém verbo, ou tem o verbo ser ocultado, o que é típico da frase nominal hebraica.

A segunda frase, "mais distinto do que dez mil", também é nominal, mas devido a ocorrência da preposição do que, a tradução portuguesa exigiu o acréscimo do vocábulo [mais] sobre o verbo ser distinto traduzido em forma de substantivo. Essa preposição hebraica caracteriza o grau comparativo que o contexto permite identificar ser de superioridade (mais distinto do que). Nota-se que o único numeral ocorrente no trecho, que foi traduzido por dez mil, também poderia ser traduzido de forma simbólica ou figurada, como multidão ou miríade, tal como se fez na Septuaginta.

Do ponto de vista da análise histórico-teológica, o v. 10 contempla a figura do amado. A amada inicia no v. $10 \mathrm{o}$ inusitado was $f$ a respeito de um personagem feminino a respeito de um personagem masculino. $\mathrm{Na}$ literatura de amor da antiguidade é raro que a mulher descreva as partes do corpo do amado. O v. 10 parece se referir ao monarca de Israel ou de

${ }^{39}$ Cf. POPE, Marvin H. Song of Songs. A new translation with introduction and commentary. Vol. 7c. The Anchor Bible. London/New Haven: Yale University Press, 1977. p. 530.

40 CORDERO, Maximiliano García. "Cantar de los Cantares. Introducción y comentário". In: Biblia comentada, Libros Sapienciales. 2. ed. Madrid: BAC, 1967.

${ }^{41}$ CASCIARO, José Maria (Org.). Sagrada Biblia. Antiguo testamento. Libros Poéticos y Sapienciales. Cantar de los Cantares. Traducción y notas. 2. ed. Pamplona: Ediciones Universidad de Navarra, 2005. p. 794. 
Judá ao fazer duas referências indiretas ao rei Davi: primeiro como uso da palavra amado que possui as mesmas consoantes que o nome de Davi; segundo o uso do numeral, que parece ser uma referência à tradição que atribuiu o cântico das filhas de Israel em louvor e comparação com o rei Saul por ocasião em que Davi havia vencido o gigante filisteu Golias: "Saul feriu os seus mil, porém, Davi seus dez mil" ( $1 \mathrm{Sm}$ 18,7.8; $21,12 ; 29,5 ; S l 3,7 ; 91,7)$. Essa observação fundamenta a tese de que Ct 5,10 seria um trecho de um epitálamo real ou de uma evocação que prestigia os noivos com a referência indireta aos antigos monarcas de Israel.

Verifica-se a aporia na tradução dos adjetivos branco e rosado que podem ter sido um fenômeno de arianização da personagem amado, de um lado, mas pode corresponder à tradição de que a família real teria a tez alva. Deve-se salientar, porém, que a primeira frase do was $f$ da amada (v. 10) pode não se referir à cor da pele do amado, mas ao aspecto geral da aparência do amado. $O$ termo pode ser traduzido de forma figurada referindo-se ao brilho da beleza do amado. A beleza dos traços e do porte do amado lhe conferem aspecto brilhante ou ilustre. O termo corado pode ser referir à saúde e à robustez do amado.

\section{Referências}

ALBRIGHT, W. F. Archaical Survivals in the text of Canticles. In: THOMAS, Winton; MCHARDY, W. D. (Org.). Hebrew and Semitic Studies Presented to Godfrey Rolles Driver. 1963.

ALONSO SCHÖKEL, Luis. Dicionário Bíblico Hebraico-Português. 3. ed. São Paulo: Paulus, 2004.

ARCONADA, R.; ARSENIO, F. Arsenio; BARTINA, S. La Sagrada Escritura. Texto y comentario. Antiguo Testamento. IV, Los Salmos y los Libros salomónicos. Juan Leal (Org.). Madrid: BAC, 1969.

ARNOLD, Bill T.; CHOI, John H. A guide to the Biblical Hebrew Syntax. New York: Cambridge University Pres, 2003.

ASENSIO, Félix. Cantar de los cantares. Traducción y comentário. In: La sagrada Escritura. Antiguo Testamento. IV. Los Salmos y los Libros salomónicos. Juan Leal (Org.). Madrid: BAC, 1969.

BIBLIA HEBRAICA STUTTGARTENSIA. 5. ed. BHS: Deutsche Bibelgesellschaft, 1997.

CARR, Lloyd. The Songs of Salomon. An Introduction \& Commentary. Leicester/ Downers Grove: Inter-varsity Press, 2005. 
CASCIARO, José Maria. Cantar de los Cantares. Introducción y notas. In: Sagrada Bíblia. Antiguo Testamento. Libros Poéticos y Sapienciales. Traducción y notas. 2. ed. Pamplona: Ediciones Universidad de Navarra, 2005.

CAVALCANTI, Geraldo Holanda. O Cântico dos Cânticos. Um ensaio de Interpretação através de suas traduções. São Paulo: Editora da Universidade de São Paulo, 2005.

CORDERO, Maximiliano García. Cantar de los Cantares. Introducción y comentário. Biblia Comenta. IV. libros Sapienciales. 2. ed. Madrid: BAC. 1967.

FRANCISCO, Edson de Faria. Manual da Bíblia Hebraica. Introdução ao Texto Massorético. Guia Introdutória para a Bíblia Hebraica Stuttgartensia. São Paulo: Vida Nova, 2008.

JOHNSTON, Gordon H. The Enigmatic Genre and Structure of the Song of Songs. Bibliotheca Sacra, 166, p. 289-305, 2009.

KEEL, Othmar. The Song of Songs. A Continental Commentary. Trad. Frederick Gaiser. Minneapolis: Fortress Press, 1994.

KELleY, Page H. Hebraico Bíblico. Trad. Marie Ann Wanger Krahn. 4. ed. São Leopoldo: Sinodal, 2003.

POPE, Marvin H. Song of Songs. A new translation with introduction and commentary. Vol. 7c. The Anchor Bible. London/New Haven: Yale University Press, 1977.

ROSS, Allen P. Gramática do Hebraico Bíblico. 2. ed. Trad. Gordon Chown. São Paulo: Editora Vida, 2008.

STADELMANN, Luis. Cântico dos cânticos. São Paulo: Loyola, 1993.

VERSIO LXX INTERPRETATUM GRAECA. Secundum Septuaginta. Vetus Testamentum Graecum auctoritate Societatis Litterarum Gottingensis editum 1931.

WALTKE, Bruce K.; O’CONNOR, M. Introdução à Sintaxe do Hebraico Bíblico. Tradução Fabiano Ferreira, Adelemir Garcia Esteves e Roberto Alves. São Paulo: Cultura Cristã, 2006. 